Journal of Telenursing (JOTING)

Volume 1, Nomor 1, Juni 2019

e-ISSN : 2684-8988

p-ISSN : 2684-8996

DOI: https://doi.org/10.31539/joting.v1i1.491

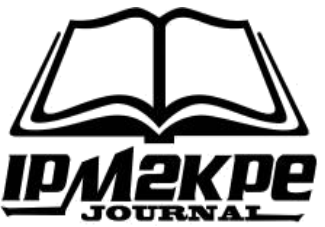

\title{
PENGARUH SELF HEALING TERHADAP PENURUNAN SKALA NYERI PASIEN POST OP
}

\author{
Ahmad Redho $^{1}$, Yani Sofiani², Anwar Wardi Warongan ${ }^{3}$ \\ Universitas Muhammadiyah Jakarta ${ }^{1,2,3}$ \\ ahmadredho49@gmail.com ${ }^{1}$
}

\begin{abstract}
ABSTRAK
Tujuan penelitian ini adalah untuk mengetahui pengaruh self healing (healing touch) terhadap penurunan sensari nyeri pasien post op di RSUD Pemerintahan Daerah Tk II Kampar Kota Bangkinang. Metode dalam penelitian ini menggunakan metode quasi eksperimen dengan pretest-postest design. Hasil analisis bivariate menunjukkan ada pengaruh yang signifikan antara Self healing dengan skala nyeri pada pasien post op dengan $\mathrm{p}$ value $<0.05$. Simpulan, self healing dijadikan sebagai salah metode non medikasi untuk menurunkan skala nyeri pada pasien post op.
\end{abstract}

Kata Kunci: Pasien Post Op, Self Healing, Skala Nyeri

\section{ABSTRACT}

The purpose of this study was to determine the effect of self-healing (healing touch) on reducing pain sensation for post-op patients at Tk II Kampar Regional Government Hospital, Bangkinang City. The method in this study used a quasi-experimental method with a pretest-postest design. The results of the bivariate analysis showed that there was a significant effect between self healing and pain scale in post op patients with p value <0.05. In conclusion, self-healing is used as one of the non-medicated methods to reduce the pain scale in post-op patients.

Keywords: Post Op Patients, Self Healing, Pain Scale

\section{PENDAHULUAN}

Pembedahan atau operasi adalah semua tindakan pengobatan yang menggunakan cara invasif dengan membuka atau menampilkan bagian tubuh yang akan ditangani (Sjamsuhidajat \& Jong, 2008). Organization (WHO) memperkirakan setiap tahun ada 230 juta operasi utama dilakukan di seluruh dunia, satu untuk setiap 25 orang hidup. Penelitian di 56 negara dari 192 negara diperkirakan ada 234,2 juta prosedur pembedahan dilakukan setiap tahun dan berpotensi menimbulkan komplikasi dan kematian. Sedangkan di Indonesia terjadi peningkatan pembedahan setiap tahunnya dimana pada tahun 2009 terdapat 46,87\% kasus pembedahan, tahun 2010 sebesar 53,22\%, tahun 2011 sebesar 51,59\%, dan tahun 2012 sebesar 53,68\% (Potter \& Perry, 2010). 
Masalah yang timbul setelah post op adalah nyeri. nyeri pasca bedah mungkin sekali disebabkan oleh luka operasi, tetapi kemungkinan sebab lain harus dipertimbangkan. Sebaiknya pencegahan nyeri direncanakan sebelum operasi agar penderita tidak terganggu pasca bedah.Analgesik sebaiknya diberikan sebelum nyeri timbul dengan dosis yang memadai. Dimensi kesadaran akan nyeri, pengalaman nyeri, dan tingkah laku penderita sangat dipengaruhi oleh antisipasi dan harapan penderita. Proses timbulnya keluhan nyeri terdapat rangsang nosisepsi yang disebabkan noksa, setelah itu penderita menyadari adanya noksa, baru kemudian mengalami sensasi nyeri dan akhirnya timbul reaksi terhadap nyeri dalam bentuk sikap dan perilaku verbal maupun nonverbal dalam menyampaikan apa yang dirasakannya (Sjamsuhidajat, 2013).

Nyeri merupakan suatu kondisi yang lebih dari sekedar sensasi tunggal yang disebabkan oleh stimulus tertentu Intensitas bervariasi mulai dari nyeri ringan sampai nyeri berat namun menurun sejalan dengan proses penyembuhan (Astuti, 2016). Manajemen nyeri yang tepat haruslah mencakup penanganan secara keseluruhan, tidak hanya terbatas pada pendekatan farmakologi saja, karena nyeri juga dipengaruhi oleh emosi dan tanggapan individu terhadap dirinya. Secara garis besar ada dua manajemen untuk mengatasi nyeri yaitu manajemen farmakologi dan manajemen non farmakologi (Pinandita, 2012). Manajemen nyeri non farmakologi perlu dilakukan oleh perawat di ruang bedah ataupun di ruangan perawatan bedah meskipun sering ditemui kendala beban kerja yang tinggi. Intervensi manajemen nyeri nonfarmakologi hasil dari beberapa banyak sekali yang bisa dilakukan terutama keluarga seperti dengan memberikan pelukan, dukungan, distraksi dan lain-lain (Ilmiasih, 2013).

Penanganan nyeri yang bisa dilakukan pasien sendiri akan meringankan beban kerja pertugas yang bisa dilakukan pasien secara mandiri. Riset modern menemukan bahwa sistem tubuh manusia tidaklah seperti yang dipercaya oleh para pakar pada era sebelumnya. Pada era sebelumnya, diyakini bahwa jiwa dan tubuh senantiasa terpisah dan memiliki mekanisme kerjanya sendiri-sendiri yang tidak memengaruhi satu sama lain. Hari ini, dunia kedokteran menemukan bahwa sistem tubuh manusia merupakan jaringan elemen-elemen yang membentuk kesatuan integral, yang mekanisme kerjanya saling mempengaruhi.Sistem tubuh yang seperti ini populer dengan sistem holistik (Ulwiya, 2014).

Self healing merupakan diantaranya yang bisa dilakukan dan tepat untuk pasien nyeri. Self healing adalah metode penyembuhan penyakit bukan dengan obat, melainkan dengan menyembuhkan dan mengeluarkan perasaan dan emosi yang terpendam di dalam tubuh.Selain itu, self-healing juga dapat dilakukan dengan hipnosis, terapi qolbu, atau menenangkan pikiran. Self healing dilakukan oleh si penderita penyakit, dan dibantu oleh terapi (Ulwiya, 2014). Self healing dengan sentuhan pada diri sendiri.Self healing adalah rangkaian latihan praktis yang dikerjakan secara mandiri sekitar 15-20 menit, dan sebaiknya dilakukan 2 kali dalam sehari. Dalam latihan self healing, ada beberapa aspek yang dilibatkan yakni napas stabil, gerak hanya untuk kesembuhan, sentuhan, dan keheningan.Seseorang yang melakukannya agar dapat berhenti sejenak dari segala rutinitasnya, sehingga bisa berinteraksi dengan diri sendiri.Self healing bersifat universal, tidak mengacu agama manapun, praktis, dan dipelajari secara masuk akal. Filosofinya bertumpu pada manusia sebagai unit yang lengkap antara badan, batin, dan kemampuan individualnya (Gunawan, 2015). 
Pada awalnya self healing ini ditujukan sebagai tindakan preventif atau pencegahan sebelum datangnya suatu penyakit. Namun demikian, saat seseorang sakit, teknik self healing tetap bisa dilakukan sembari melakukan pengobatan medis termasuk nyeri.Self healing dengan sentuhan (touch healing) bukanlah prana, sugesti, tapi ini real. Walaupun seseorang bahkan tidak sadar bahwa hal yang dilakukan sehari-hari adalah self healing (Rachman, 2015). Penelitian Mumpuni (2014) Hasil penelitian menunjukkan adanya perbedaan yang signifikan antara skala nyeri sebelum dan sesudah tindakan baik pada kelompok intervensi maupun kelompok kontrol (nilai p =0,000). Hasil uji Mann-Whitney pun memperlihatkan adanya perbedaan yang signifikan pada penurunan skala nyeri antara kelompok intervensi dengan kelompok kontrol (nilai $\mathrm{p}=0,000$ ).

Sebelumnya Marta (2010) pernah melakukan penelitian tentang Efektivitas touch terapeutik pada rasa sakit, depresi dan tidur pada pasien dengan rasa sakit kronis: percobaan klinis. Penelitian dilakukan di Unit Kesehatan Dasar di Fernandópolis, SPBrasil, melibatkan 30 pasien lanjut usia dengan nyeri non-onkologis kronis yang menerima 8 sesi Terapi Sentuhan sesuai dengan metode krieger-kunz. Skala analog visual untuk rasa sakit diterapkan sebelum dan sesudah setiap sesi, dan beck depression inventory dan pittsburgh sleep quality index sebelum sesi pertama dan setelah sesi terakhir. Analisis data menunjukkan penurunan yang signifikan $(\mathrm{p}<0,05)$ pada intensitas nyeri, skor penilaian diri depresi dan indeks kualitas tidur.

Penelitian Anderson (2015) tentang Efek penyembuhan dengan sentuhan pada rasa sakit, mual, dan kecemasan setelah bedah bariatric. Pada Studi Pendahuluan mendapatkan adanya penurunan rasa sakit, mual, dan kegelisahan yang signifikan terjadi segera setelah intervensi pada hari pasca operasi satu dan dua, dan pada rasa sakit dan kecemasan pada hari pasca operasi tiga dibandingkan dengan tingkat pra-intervensi. Temuan ini menunjukkan bahwa intervensi penyembuhan sentuhan layak dilakukan dan dapat diterima oleh pasien yang menjalani operasi bariatrik, dan secara signifikan meningkatkan rasa sakit, mual, dan kecemasan pada pasien ini.

Berdasarkan penelitian yang dilkukan Thomas (2013) menjelaskan bahwa efektifitas sentuhan (healing touch) untuk kesembuhan nyeri, stress dan kecemasan dan nyeri dengan penggunaan obat-obatan yang bertujuan untuk mengetahui efektifitas penyembuhan dengan sentuhan (touch), kecemasan dan stress, rasa sakit dan penggunaan obat nyeri yang di berikan selama 30 menit dengan metode control dan acak dengan membandingkan HTM (Healing Touch Music) namun tidak bisa digeneralisasikan. Namun dalam review studi tentang penyembuhan sentuhan (Healing Touch) pada lebih dari 30 penelitian yang telah dilakukan dengan sentuhan penyembuhan (Healing Touch) sebagai variabel indefendent tidak ada hasil yang dapat digeneralisasi, Namun hendaknya ada penelitian selanjutnya untuk membuktikannya (Werdell \& Weymouth, 2004).

\section{METODE PENELITIAN}

Penelitian ini menggunakan metode kuasi eksperimen dengan desain pretest dan posttest. Populasi dalam penelitian ini adalah semua pasien post operatif yang dirawat di RSUD Bangkinang Kabupaten Kampar periode 14 mei 2018 sampai 03 juli 2018 yang berjumlah 41responden namun yang termasuk dalam kategori inklusi sebanyak 39 responden. Sampel sesuai dengan kriteria inklusi : 1) Pasien post operasi 2) Pasien dalam keadaan sadar 3) Pasien mengalami nyeri dengan skala ringan sampe sedang 4) Pasien 
berumur 12- 65 tahun 5) Mampu berkomunikasi secara verbal serta kriteria eksklusi : 1)Pasien tidak bersedia 2) Pasien dengan fraktur di ekstremitas.

\section{HASIL PENELITIAN \\ Analisis Univariat \\ Karakteristik Responden}

Tabel. 1

Distribusi Frekuensi Usia Responden Berdasarkan

Karakteristik Post Operasi ( $\mathrm{n}=39)$

\begin{tabular}{cccccc}
\hline No & Variabel & Mean & SD & Min-Max & CI 95\% \\
\hline 1 & Usia & 40.92 & 12.042 & $12-62$ & 37.02 \\
\hline
\end{tabular}

Berdasarkan tabel 1 didapatkan rata-rata usia pasien post op adalah 40.92 tahun dari $39(100 \%)$ responden dengan usia terendah 12 tahun dan yang tertinggi 62 tahun dengan standar deviasi 12.042 .

Tabel. 2

Distribusi Frekuensi Responden Berdasarkan Karakteristik Post Operasi $(\mathrm{n}=39)$

\begin{tabular}{lllcc}
\hline No & Jenis Data & Kategorik & Jumlah $(\mathrm{n})$ & Persentase $(\%)$ \\
\hline 1. & Jenis Kelamin & Laki-laki & 15 & 38.5 \\
& & Perempuan & 24 & 36.1 \\
\hline 2. & Pengalaman Nyeri & Ya & 39 & 100 \\
& & Tidak & 0 & 0 \\
\hline 3. & Medikasi & Tidak & 0 & 0 \\
& & Ya & 100 & 0 \\
\hline
\end{tabular}

Berdasarkan tabel 2 distribusi frekuensi jenis kelamin responden yang terbesar adalah perempuan 25 (36.1\%), dengan rata-rata semua responden mempunyai pengalaman nyeri $39(100 \%)$ dan responden yang mendapatkan medikasi analgetik responden 39 $(100 \%)$.

Tabel. 3

Gambaran Perubahan dan Rata-Rata Skala Nyeri

Sebelum dan Sesudah Perlakuan $(n=39)$

\begin{tabular}{ccccc}
\hline \multirow{2}{*}{ Pengukuran } & \multicolumn{3}{c}{ Penurunan Skala Nyeri } & \multirow{2}{*}{ CI 95\% } \\
\cline { 2 - 4 } & Mean & Standar Deviasi & Min-Max & \\
\hline Sebelum & 43.46 & 13.103 & $20-70$ & \\
Sesudah & 26.74 & 11.311 & $9-60$ & $14.352-18.776$ \\
\hline
\end{tabular}


Berdasarkan tabel 3 didapatkan rata-rata skala nyeri sebelum intervensi 43.46 dengan standar deviasi 13.103 dengan skor terendah 20 dan tertinggi 70, sedangkan ratarata skala nyeri sesudah intervensi rata-rata 26.74 dengan standar deviasi 11,311, skor terendah 9 dan tertinggi 60.

\section{Analisis Bivariat}

Tabel. 4

Analisis Perubahan Skala Nyeri Sebelum dan Setelah Self Healing pada Pasien Post Op (n=39)

\begin{tabular}{|c|c|c|c|c|c|c|}
\hline \multirow[b]{2}{*}{ Jenis Kelompok } & \multicolumn{2}{|c|}{ Skala Nyeri } & \multirow[b]{2}{*}{ Mean } & \multirow[b]{2}{*}{ SD } & \multirow[b]{2}{*}{ SE } & \multirow{2}{*}{ P Value } \\
\hline & Sebelum & Sesudah & & & & \\
\hline Self Healing & 43.46 & 26.90 & 16.564 & 6.824 & 1.093 & 0.000 \\
\hline
\end{tabular}

Berdasarkan tabel 4 memperlihatkan perbedaan hasil skala nyeri setelah mendapatkan intervensi self healing terjadi penurunan skala nyeri pada responden yang mendapatkan self healing menurun secara bermakna sebesar 16.564 dengan $\mathrm{p}$ value $<0.05$. Ada perbedaan skala nyeri sebelum dilakukan intervensi dengan setelah dilakukan intervensi.

\section{PEMBAHASAN}

\section{Karakteristik responden}

\section{Usia}

Dalam penelitian ini menunjukkan umur responden pada post operasi yang mendapatkan intervensi self healing yang terbanyak berada pada rentang 36 sampai 45 tahun. Usia merupakan salah satu faktor fisiologis yang secara langsung dapat mempengaruhi intensitas nyeri pasien pasca bedah. Hasil penelitian ini sesuai dengan teori dimana lanjut usia (lansia) berespon terhadap nyeri dapat berbeda dengan cara berespon orang yang berusia lebih muda (Smeltzer \& Bare, 2012). Beberapa faktor yang memengaruhi respon orang tua antara lain orang tua berpendapat bahwa nyeri yang terjadi merupakan sesuatu yang harus mereka terima (Potter \& Perry, 2005). Kebanyakan orang tua takut terhadap efek samping obat dan menjadi ketergantungan, sehingga mereka tidak melaporkan nyeri atau menanyakan obat untuk menghilangkan nyeri (Lemone \& Burke, 2008).

\section{Jenis Kelamin}

Hasil penelitian yang menunjukan bahwa perempuan mengalami intensitas nyeri lebih tinggi daripada laki-laki. Hal ini sesuai dengan penelitian yang dilakukan oleh YuanYi, et al., (2012) mengenai korelasi karakteristik pasien, dan hubungan pasca bedah dengan kebutuhan morpin dan penilaian nyeri saat istirahat dan bergerak. Penelitian dilakukan dengan jumlah total responden sebesar 2.298 yang menerima morpin. Hasil penelitian menunjukan bahwa laki-laki kurang mengkonsumsi morpin melalui PCA daripada perempuan pada hari pertama sampai hari ketiga pasca bedah $(\mathrm{P}<0,05)$. 
Sedangkan secara teori menyatakan laki-laki memiliki sensitifitas yang lebih rendah (kurang mengekspresikan nyeri yang dirasakan secara berlebihan) dibandingkan wanita atau kurang merasakan nyeri (Smeltzer \& Bare, 2012).

\section{Budaya}

Berdasarkan karakteristik budaya, sebagian besar responden atau sekitar 31 orang (79.5\%) memiliki budaya melayu. Budaya mempengaruhi seseorang bagaimana cara toleransi terhadap nyeri, mengintepretasikan nyeri, dan bereaksi secara verbal atau nonverbal terhadap nyeri (LeMone \& Burke, 2008). Hasil penelitian yang dilakukan oleh Wijaya (2015) menyatakan bahwa setiap orang dengan budaya yang berbeda akan mengatasi nyeri dengan cara yang berbeda-beda. Orang yang mengalami intensitas nyeri yang sama mungkin tidak melaporkan atau berespon terhadap nyeri dengan cara yang sama. Ada perbedaan makna dan sikap yang dikaitkan dengan nyeri pada berbagai budaya.

\section{Pengalaman Nyeri}

Hasil penelitian menunjukan bahwa intensitas nyeri pasien pasca bedah pada pengalaman nyeri sebelumnya tidak pernah mengalami nyeri sebelumnya lebih tinggi daripada responden yang pernah mengalami nyeri sebelumnya. Hasil penelitian ini sesuai dengan penelitian yang dilakukan oleh Potter \& Perry (2005) menemukan bahwa 29\% wanita dengan pembedahan abdomen histerektomy dilaporkan mempunyai nyeri yang lebih hebat daripada pengalaman nyeri pembedahan abdomen sebelumnya. Sisanya $71 \%$ wanita yang dilakukan histerektomi mangalami nyeri ringan atau sama seperti pengalaman nyeri sebelumnya.

Hal ini senada dengan teori yang menyatakan responden yang pernah mengalami nyeri sebelumnya memiliki intensitas nyeri yang lebih rendah dibandingkan yang tidak pernah mengalami nyeri sebelumnya, karena nyeri sebelumnya berhasil dihilangkan, maka akan lebih mudah bagi individu tersebut untuk melakukan tindakan-tindakan yang diperlukan untuk menghilangkan nyeri (Potter \& Perry, 2005).

\section{Pemberian Medikasi}

Hasil penelitian menunjukkan bahwa karakteristik medikasi analgetik 39 responden (100\%). Nyeri paska bedah umumnya disebabkan kerusakan jaringan yang tidak dapat dihindari. Nyeri pasca bedah tidak diperbolehkan mengganggu penyembuhan pasien sehingga diberikan penanganan dengan regimen analgetik yang adekuat namun tidak berlebihan untuk mencegah terjadinya efek samping analgetika yang digunakan.

Penanganan nyeri pasca bedah paling sering menggunakan regimen analgetik: ketorolak, parasetamol dan tramadol. Analgesia merupakan salah satu pilihan yang sering digunakan agar mencapai efek terapeutik yang adekuat dengan meminimalisir efek samping dengan mengkombinasikan lebih dari satu macam analgetika.Selain hal tersebut pemberian analgetika juga disesuaikan dengan skala nyeri yang ditentukan dengan VAS (Saputra, 2013). 


\section{Pengaruh Self Healing terhadap Penurunan Skala Nyeri Pasien Post Operasi}

Hasil penelitian ini menunjukkan bahwa rata-rata skala nyeri setelah dilakukan intervensi mengalami penurunan. Hal ini sesuai dengan konsep dimana teknik self healing melibatkan sentuhan yang dijelaskan dalam istilah "hands in motion" (digunakan untuk menghilangkan kemacetan atau kerapatan dari medan energi) atau "tangan diam" (digunakan untuk membangun kembali energi arus dan keseimbangan) serta folus pada diri penderita (Schommer \& Larrimore, 2010).

Dengan gerak tangan, tangan membuat gerakan menyikat atau menyisir lembut, biasanya ke bawah dan ke luar, untuk menghilangkan energi yang padat dari lapangan.Tangan tetap rileks, telapak tangan menghadap ke bawah ke arah pasien, antara 1 inci dan 6 inci di atas kulit atau pakaian.Stroke tangan mungkin lamban dan menyapu atau pendek dan cepat.

Dengan tangan kanan menggengam pergelangan tangan kiri dibawah tekukan sedangkan jari-jari lurus terbuka sejajar jantung atau lebih tinggi dengan rileks menghadap kedepan, sambil berkonsentrasi pada dirinya untuk kesembuhannya. Di posisi tangan-diam, memegang tangan selama beberapa menit, dengan ringan menyentuh kulit tanpa menggengam kuat. Fokus dengan dirinya dan memantapkan diri untuk sembuh. Hal yang dirasakan adalah perasaan "luar biasa", "santai," "damai," "dalam keadaan meditasi," "hangat," "ditenangkan," "aman," "diyakinkan," "lebih seimbang , "Mellow," "lebih bahagia dengan kehidupan," "seolah-olah semua ketegangan saya mencair," dan "perasaan kedamaian batin" (Umbreit, 2014).

Teknik self healing dapat memodulasikan nyeri melalui pengeluaran endorphin dan enkefalin. Menurut teori perubahan hormone mengemukakan tentang peranan endorphin yang merupakan substansi atau neurotransmitter menyerupai morfin yang dihasilkan tubuh secara alami. Neurotrasmiter tersebut hanya bisa cocok pada reseptor-reseptor pada syaraf yang secara spesifik dibentuk untuk menerimanya. Keberadaan endorphin pada sinap selsel saraf mengakibatkan penurunan sensasi nyeri (Kastono, 2008). Peningkatan B endorphin terbukti berhubungan erat dengan penurunan rasa nyeri. Ketika sedang kesakitan akibat terjatuh atau tergores luka, atau pasca operasi nyeri bisa bekurang dengan self healing. Hal ini sesuai dengan mini studi di Finlandia yang menunjukkan bahwa kontak tubuh berupa sentuhan yang lembut penyebabkan penurunan opioid alami di daerah otak yang berhubungan dengan sirkulasi reward otak.

Selain itu self healing akan membuat perubahan-perubahan di dalam tubuh, seperti mengurangi ketegangan otot, menurunkan konsumsi oksigen, pernafasan dan meningkatkan produksi serotonin yang menimbulkan perasaan tenang dan sejahtera dengan demikian akan mengurangi nyeri. Serotonin merupakan neurotransmiter yang memiliki andil dalam memodulasi nyeri pada susunan saraf pusat. Ia berperan dalam system analgesik otak.Serotonin menyebabkan neuron-neuron lokal medulla spinalis mensekresi enkefalin. Enkefalin dianggap dapat menimbulkan hambatan presinaptik dan postinaptik pada serabutserabut nyeri. Analgesic ini dapat memblok sinyal nyeri pada tempat masuknya ke medulla spinalis.

Proses yang terjadi pada self healing berawal pada proses transmisi (transmission) saat terjadi sentuhan didaerah pergelangan tangan maka terjadi proses transduksi impuls disalurkan melalui serabut c sebagai neuron pertama dari perifer ke medula spinalis dimana impuls tersebut mengalami modulasi sebelum diteruskan ke thalamus oleh traktus 
sphinotalamikus sebagai nuron kedua dari thalamus selanjutnya disalurkan ke daerah somatosentris dikorteks sebral melalui neuron ketiga dan diterjemahkan sebagai persepsi nyeri.

Kemudian dilanjutkan pada proses modulasi (modulation) dimana terjadi interaksi antara sistem analgesik endogen yang dihasilkan oleh tubuh pada saat nyeri masuk ke kornu posterior di medula spinalis dan dikontrol oleh otak. Sistem analgesik endogen ini meliputi enkafalin, endorphin, serotonin, dan non adrenalin yang memiliki efek yang dapat menekan impuls nyeri pada kornu posterior medulla spinalis.Kornu posterior merupakan pintu yang dapat terbuka dan tertutup, proses ini menyebabkan pada setiap orang sangat subjektif.

Setelah itu nyeri akan membentuk persepsi, yaitu pada saat seseorang sedang mneyadari adanya nyeri maka terjadi reaksi kompleks. Tubuh akan mengidentifikasi intensitas, jenis, dan lokasi nyeri, sekaligus menghilangkan sensasi nyeri dengan pengalaman masa lalu, memori, aktifitas kognitif. Kemudian system limbik akan bertanggung jawab merespon nyeri melalui emosi dan perilaku seperti perhatian, senang serta pengolahan nyeri (Black, 2009).

Hal ini senada dengan penelitian Budiman \& Ardianty (2017) Usui Reiki Ryoho Gakkai yang berkedudukan di Tokyo serta mendirikan klinik reiki di Harajuku, Aoyama. Melalui organisasi inilah Master Mikao Usui melakukan penyembuhan dengan reiki dan mulai mengajarkan reiki kepada masyarakat sekitar. Filosofi reiki tentang munculnya gangguan psikologis di atas memiliki kesamaan dengan mekanisme terjadinya stres dari sisi biologis. Menurut teori James-Lange situasi yang menghasilkan emosi akan mendatangkan respon-respon yaitu otonom, perilaku serta endokrin (Ishaq 2007).

Hasil penelitian ini berdasarkan nilai rata-rata nyeri intervensi sebelum adalah 69,37 $(\mathrm{SD}=10,52)$, sedangkan skor nyeri pada saat posttest adalah 63,81 $(\mathrm{SD}=09,47)$, dimana terdapat penurunan angka nyeri setelah diberikan intervensi self healing dengan energi reiki dengan nilai $\mathrm{P}$ value 0,00 diartikan mampu mengurangi tingkat nyeri dalam waktu singkat. Energi reiki merupakan energi yang dapat diakses dari alam semesta dan disalurkan ke dalam tubuh eterik (tubuh halus/sukma). Terapi self healing dapat dijadikan alternatif terapi dalam mengurangi dan mengatasi kecemasan.

\section{SIMPULAN}

Berdasarkan hasil penelitian dapat disimpulkan bahwa penelitian yang dilakukan memberikan gambaran karakteristik pasien post op di RSUD Bangkinang Kabupaten Kampar yang terdiri dari 39 responen sebagian besar berusia 36-45 tahun dengan jenis kelamin sebagian besar perempuan dan di dominasi oleh pasien yang bekerja sebagai IRT. Terdapat perbedaan yang bermakna penurunan tingkat nyeri pasien post op sesudah pengaruh self healing pada kelompok intervensi dengan rata-rata penurunan. Terdapat pengaruh self healing terhadap penurunan tingkat nyeri pada pasien post op.

\section{SARAN}

Bagi pelayanan keperawatan self healing dapat dijadikan kompetensi bagi perawat dalam manajemen nonfarmakologi penanganan nyeri di Rumah Sakit pada pemberian asuhan keperawatan yang mengalami nyeri post operasi sebagi terapi komplementer serta mengurangi resiko terpapar bahan kimiawi seperti obat-obatan. 
Bagi pendidikan keperawatan hasil penelitian Self haling memberikan hasil yang signifikan sehingga dapat diaplikasikan pada kurikulum mata ajar manajemen nyeri secara non farmakologi bagi mahasiswa perawat dalam memenuhi kebutuhan dasar manusia.

Bagi peneliti selanjutya perlu adanya penelitian lanjutan terkait dengan faktor-faktor keberhasilan tindakan self healing dalam mengurangi nyeri pasien post op perlu adanya penelitian terkait dengan sampel yang homogenik atau membandingkan dengan teknik untuk menurunkan skala nyeri lainya.

\section{DAFTAR PUSTAKA}

Anderson, A. (2015). The Effects of Healing Touch on Pain, Nausea and Anxiety Following Bariatric Surgery: A Pilot Study. Diakses pad maret 2018. http://www.explorejournal.com/article/S1550-8307(15)00032-4/fulltext

Astuti, A. (2016). Pengaruh Music Klasik terhadap Penurunan Tingkat Skala Nyeri Pasien Post Operasi. Jurnal Ipteks Terapan, 10

Black, M. (2009). Keperawatan Medikal Bedah. Edisi 8, Buku 1. Elseivier

Budiman., B., \& Ardianty, S. (2017). Pengaruh Efektivitas Terapi Self Healing Menggunakan Energi Reiki terhadap Kecemasan Menghadapi Ujian Skripsi. Jurnal Ilmiah Psikologi, 4(1), 141-148

Gunawan, G. (2015). Sehat dengan Self Healing, Karena Tiap Orang adalah Penyembuh Terbaik bagi Diri Sendiri. Diakses April 2018. https://health.detik.com/beritadetikhealth/d-2808275/self-healing-karena-tiap-orang-adalah-penyembuh-terbaikbagi-diri-sendiri

Ishaq, I. (2007). Mengenal Usui Reiki I dan II Intensif, Jakarta: Delaprasta Publishing Kastono, R. (2008). Struktur dan Fungsi Sistem Syaraf Manusia. Bandung: Yrama Widya Lemone, P., \& Burke. M. K. (2008). Medical Surgical. New Jersey: Pearson education Inc Marta, M. (2010). The Effectiveness of the Therapeutic Touch on Pain, Depresion and Sleep in Patiens With Chronic Pain : Clinical Trial, Original Artikel

Mumpuni, M. (2014). Therapeutic Touch and Post-Operative Pain. Jurnal Kesehatan Masyarakat Nasional, 8(6)

Pinandita, P. (2012). Pengaruh Teknik Relaksasi Genggam Jari terhadap Penururnan Intensitas Nyeri pada Pasien Post Operasi Laparatomi

Potter, P. A., \& Perry, A. G. (2005). Fundamental of Nurssing, (6thEd), St. Mo : Mosby

Potter, P., \& Perry, P. (2010). Fundamental of Nursing Buku 3 Edisi 7. Elseiver: Salemba Medika

Rachman, R. (2015). Ruang Perawatan Intensive Literature Review. Volume 1

Saputra, L. (2013). Pengantar Kebutuhan Dasar Manusia. Tangerang: Binarupa Aksara

Schommer, S., \& Larrimore, L. (2010). Complementary \& Alternative Therapies in Nursing Seventh Edition Springer Publishing Company, LLC Copyright (C) 2014

Sjamsuhidajat, R., \& Jong, W. D. (2008). Buku Ajar Ilmu Bedah. Jakarta: EGC

Sjamsuhidajat, S. (2013). Buku Ajar Ilmu Bedah. Edisi 3. Jakarta: EGC

Smeltzer, S., \& Bare, B. (2012). Buku Ajar Keperawatan Medikal Bedah .Edisi 8. Jakarta: EGC

Thomas, S. P. (2013). Infeksi Luka Operasi (ILO) pada Pasien Post Operasi Laparatomi. Jurnal Keperawatan Terapan, 1(1), 14-24 
Ulwiya, U. (2014). Mengapa Self Healing. Di akses pada Juli 2018 melalui http://aquariuslearning.co.id/mengapa-self-healing/

Umbreit, A. W. (2014). Complementary \& Alternative Therapies in Nursing Seventh Edition Springer Publishing Company, LLC Copyright (C) 2014

Werdell, W., \& Weymouth, W. (2004). Review of Studies of Healing Touch. Journal Of Nursing Scholarship, 36(2), 147-154. DOI: https://doi.org/10.1111/j.15475069.2004.04012.x

Wijaya, S. (2015). Majalah Peran Pembedahan pada Tumor Jinak Payudara. Kedokteran Andalas, 38(1). http://jurnalmka.fk.unand.ac.id

Yuan-Yi, C., Lok-Hi, C., Chun-Chieh, H., Liu, K., Luo-Ping, G., \& Pei-Ning, W. (2012). Gender and Pain Upon Movement are Associated with the Requirements for Postoperative Patient-Controlled iv Analgesia: a Prospective Survey of 2,298 Chinese patients. Canadian Journal of Anesthesia, 49, 249-255. http://www.ncbi.nlm.nih.gov/pubmed/11861342 